\title{
AIBP and APOA-I synergistically inhibit intestinal tumor growth and metastasis by promoting cholesterol efflux
}

Tao Zhang ${ }^{1,2}$, Qilong Wang ${ }^{1}$, Yeqi Wang ${ }^{1}$, Junping Wang ${ }^{2}$, Yongping Su ${ }^{2}$, Fengchao Wang ${ }^{2 *}$ and Guixue Wang ${ }^{1 *}$ (D)

\begin{abstract}
Background: The roles played by cholesterol in cancer development and progression represent a popular field in the cancer community. High cholesterol levels are positively correlated with the risk of various types of cancer. APOA-I binding protein (AIBP) promotes the reverse cholesterol transport pathway (RCT) in cooperation with Apolipoprotein A-I (APOA-I) or high-density lipoprotein cholesterol. However, the combined effect of AIBP and APOA-I on intestinal tumor cells is still unclear.
\end{abstract}

Methods: Immunohistochemistry, western blot and qPCR were performed to investigate the expression of AIBP and APOA-I in intestinal tumor tissues and cell lines. The anti-tumor activity of AIBP and APOA-I was evaluated by overexpression or recombinant protein treatment. Cholesterol efflux and localization of lipid raft-related proteins were analyzed by a cholesterol efflux assay and lipid raft fraction assay, respectively.

Results: Here, we reported that both AIBP expression and APOA-I expression were associated with the degree of malignancy in intestinal tumors. Co-overexpression of AIBP and APOA-I more potently inhibited colon cancer cell-mediated tumor growth and metastasis compared to overexpression of each protein individually. Additionally, the recombinant fusion proteins of AIBP and APOA-I exhibited a significant therapeutic effect on tumor growth in $\mathrm{Apc}^{\mathrm{min} /+}$ mice as an inherited intestinal tumor model. The synergistic effect of the two proteins inhibited colon cancer cell migration, invasion and tumor-induced angiogenesis by promoting cholesterol efflux, reducing the membrane raft content, and eventually disrupting the proper localization of migration- and invasion-related proteins on the membrane raft. Moreover, cyclosporine A, a cholesterol efflux inhibitor, rescued the inhibitory effect induced by the combination of AIBP and APOA-I.

Conclusions: These results indicate that the combination of APOA-I and AIBP has an obvious anticancer effect on colorectal cancer by promoting cholesterol efflux.

Keywords: AIBP, APOA-I, RCT, Colorectal cancer, Cholesterol efflux

\footnotetext{
*Correspondence: Wfch@tmmu.edu.cn; wanggx@cqu.edu.cn

${ }^{1}$ Key Laboratory for Biorheological Science and Technology of Ministry of Education, State and Local Joint Engineering Laboratory for Vascular Implants, Bioengineering College of Chongqing University, Chongqing, China

${ }^{2}$ Institute of Combined Injury, State Key Laboratory of Trauma, Burn and Combined Injury, Third Military Medical University, Chongqing, China
} 


\section{Background}

Cholesterol is essential for maintaining both animal cell membrane architecture and cell signaling [1, 2]. The intestine is one of the main organs for cholesterol absorption and excretion in mammals, and aberrant regulation of cholesterol metabolism has long been linked to the gastrointestinal cancer risk [3-5]. Lipid rafts, as cholesterol-enriched plasma membranes, play an active role in the regulation of cell proliferation, apoptosis, migration and invasion, which are important biological processes involved in cancer initiation, development and progression [6-8]. Thus, many functional responses are probably caused by direct or indirect modulation of the membrane cholesterol content, which may be a potential target for anticancer therapy.

APOA-I, a major protein component of HDL, contributes to the RCT pathway and is considered a potential therapeutic agent for preventing a variety of inflammation-related diseases, including cancer $[9,10]$. Clinically, the concentrations of HDL and APOA-I were found to be inversely associated with the risk of colon cancer [11]. Genetic interference with APOA-I levels in vivo exacerbates dextran sulfate sodium (DSS)-induced colitis and colitis-associated carcinogenesis, suggesting that APOAI plays a protective role in colorectal cancer progression [12]. Recently, AIBP was reported to cooperate with HDL to reduce the lipid raft content of endothelial cells by accelerating cholesterol efflux, leading to restriction of cell migration and angiogenesis in vivo and in vitro [13, 14]. In another study, AIBP promoted APOA-I binding to ATP-binding cassette transporter member 1 (ABCA1) on the cell membranes of macrophages to enhance cholesterol efflux, prevented lipid accumulation and reduced foam cell formation [15]. Early studies reported that treating enterocytes with a polyclonal antibody against AIBP inhibited [ ${ }^{125} \mathrm{I}$ ] HDL degradation and binding to cholesterol-loaded cells, suggesting that the synergy of AIBP and APOA-I/HDL in regulating cholesterol metabolism may be a universal phenomenon in mammalian cells [16]. Therefore, we hypothesized that this synergy affects intestinal epithelial tumor development and cancer cells' biological behavior.

To test the hypothesis, we first evaluated the correlation between AIBP/APOA-I expression and intestinal malignant tissues. Then, we examined the synergistic effect of AIBP and APOA-I on intestinal tumor growth and metastasis, as well as cell proliferation, viability, apoptosis, migration, and invasion and tumor-induced angiogenesis. Finally, we further explored the underlying mechanism involved. This study not only expands our understanding of AIBP and APOA-I functions but also provides some new ideas for the development of novel anticancer strategies targeting cholesterol metabolism.

\section{Methods}

Cell culture

All cell lines were obtained from the Cell Bank of Chinese Academy of Sciences (Shanghai, China, 2016). LIM1863, HIECs, HISCs and HUVECs were maintained in RPMI 1640 medium (Invitrogen Gibco, USA). Caco2, HEK293, HCT116, SW480, SW620, HT29, 841, LS174T, RKO and LOVO cells were maintained in DMEM (Invitrogen Gibco, USA). All culture media contained 10\% FBS (Invitrogen Gibco, USA). All cell lines were authenticated and tested negative for mycoplasma contamination by the providers. And the information of the cell lines are listed in Additional file 2: Table S1.

\section{Lentiviral vector construction and cell transfection}

Lentiviral-based expression vectors containing fulllength human AIBP, APOA-I or a negative control (NC) coding DNA sequence (CDS) driven by EF1 $\alpha$ were provided by GenePharma (Shanghai, China). Cells were transfected according to the manufacturer's instructions (GenePharma, China).

\section{Colony formation and CCK-8 assays}

Stably transfected cells were seeded at approximately 300 cells/well in a 6-well plate. Two weeks later, colony formation was analyzed as previously described [17]. Moreover, cells were seeded at approximately 1000 cells/ well in a 96-well plate, and CCK-8 assays were performed according to the manufacturer's protocol (7 Sea Biotech, China).

\section{Wound healing assay}

The stably transfected cells were seeded in fibronectincoated 6-well plates and cultured to confluence. Cells were serum-starved for $6 \mathrm{~h}$ and then incubated at $37{ }^{\circ} \mathrm{C}$ in 5\% lipoprotein-deficient serum (AngYuBio, China) and DMEM. The wound healing assay was performed as previously described [18].

\section{Migration and invasion assay}

Serum-starved HCT116 cells $\left(2 \times 10^{5}\right.$ cells $)$ were collected from the plate, washed, re-suspended in 5\% LPDS/ DMEM and added to the transwell $(8.0-\mu \mathrm{m}$ pore size) or another transwell coated with purified fibronectin at $(20 \mu \mathrm{g} / \mathrm{ml}$, Sigma $)$ for migration and invasion assays, respectively. Subsequently, cells were seeded into transwell chambers in the presence or absence of CsA (10 $\mu \mathrm{M}$, Sigma-Aldrich, USA). After $48 \mathrm{~h}$ of incubation, the cells that transmigrated onto the lower surface of the filter were stained with crystal violet and counted under a microscope (Olympus, Japan). Three independent experiments were conducted, and the data are presented as the mean \pm SD. 


\section{Mouse xenografts and in vivo studies}

The stably transfected cells $\left(5 \times 10^{6}\right.$ cells $)$ were implanted into the flanks of BALB/c male nude mice (Nanjing, China). Because all lentiviral-based cells were marked by GFP, tumor growth was monitored in vivo 21 days after transplantation with a Kodak In-Vivo FX professional imaging system (Connecticut, USA). APOA-I recombinant protein $(0.5 \mathrm{mg} / \mathrm{kg}$, Sino Biological) was administered subcutaneously once every 3 days at a site away from the cell implantation location. Tumor size was determined by measuring the tumor length (a) and width (b). Tumor volume (V) was calculated according to the formula $\mathrm{V}=(\mathrm{ab})^{2} / 2$. Additionally, we generated a recombinant protein containing AIBP fused to the C-terminal of full-length APOA-I and linked by peptides Pro-Gly-Ser-Gly-Ser-Gly, which was designated as R-AIBP + APOA-I. R-AIBP + APOAI, recombinant APOA-I proteins (Sino Biological) and the APOA-I mimetic D-4F (Ac-DWFKAFYDKVAEKFKEAF-NH2) (OntoRes), which were used to treat the C57BL/6J-Apc ${ }^{\mathrm{Min} /+}$ mice (Jackson Laboratory). The mice were treated intravenously with BSA $(n=8), D-4 F$ $(n=6)$, APOA-I $(n=6)$ or the AIBP + APOA-I combination $(\mathrm{n}=7)(0.5 \mathrm{mg} / \mathrm{kg})$ daily until the first tumors from randomly selected mice were detectable, and the mice were then intraperitoneally injected $(10 \mathrm{mg} / \mathrm{ani}$ mal) thrice per week until they reached 20 weeks of age. Statistical analysis of the tumor number and size was performed.

\section{Liver metastasis assay}

For liver metastasis studies, 8- to 9-week-old male $\mathrm{BALB} / \mathrm{c}$ nude mice were used. The abovementioned stably transfected colon cancer cells were harvested and mixed with $50 \%$ Matrigel at a concentration of $2 \times 10^{5}$ cells per $\mathrm{ml}$. Experimental liver metastases were generated by intrasplenic injections of $1 \times 10^{4}$ cells $(50 \mu \mathrm{l}$ of cell suspension). After 28 days, liver metastatic foci and mouse survival were analyzed.

\section{Cholesterol efflux assay}

The stably transfected cells $\left(2 \times 10^{5}\right.$ cells $)$ or HCT116 cells were treated with BSA, APOA-I, AIBP or the AIBP + APOA-I combination for $6 \mathrm{~h}$ at $37^{\circ} \mathrm{C}$ in 5\% LPDS and DMEM or EBM. Then, cholesterol efflux assays were performed using the Cholesterol Efflux Fluorometric assay kit (Biovision, USA) according to the manufacturer's instructions. The following equation was used to calculate the cholesterol efflux percentage: \% Cholesterol efflux $=$ (Fluorescence intensity of the media) $/$ (Fluorescence intensity of the cell lysate + media $) \times 100$.
ELISA

Cell culture supernatants and mouse sera were collected and assayed using APOA-I (R\&D Systems, USA) and AIBP (Aviva Systems Biology, China) ELISA kits according to the manufacturer's protocol.

\section{Cell fractionation}

The stably transfected cells receiving treatment were plated onto $10-\mathrm{cm}$ dishes at $1 \times 10^{6}$ cells per dish. Cells without any modifications were treated with $\mathrm{M} \beta C D$ (10 mM, Solarbio Life Sciences, China) for $20 \mathrm{~min}$ and washed twice with ice-cold PBS; the cytosolic fraction $(1 \mathrm{ml})$ was extracted using the ProteoExtract Subcellular Proteome Extraction kit (Merck, Germany). Triton X-100 soluble materials were extracted with $500 \mu \mathrm{l}$ of TNE buffer ( $25 \mathrm{mM}$ Tris- $\mathrm{HCl}, 0.15 \mathrm{mM} \mathrm{NaCl}, 5 \mathrm{mM}$ EDTA, and protease inhibitors) containing $1 \%$ Triton X-100. Insoluble materials were further extracted with $250 \mu \mathrm{l}$ of TNE buffer containing 1\% SDS. Equal amounts of protein from each fraction were analyzed by western blot.

\section{Western blotting}

Western blot analysis was performed with reference to a standard protocol [19]. The following primary antibodies were used: APOA-I (Bioss, Beijing, China); integrin $\beta 1$, CAV- 1 and VEGFR2 (CST, Danvers, MA, USA); and $\beta$-actin and GAPDH (Beyotime, Shanghai, China). Other primary antibodies were purchased from Abcam (Cambridge, MA, USA) using the recommended concentrations in accordance with the manufacturer's instructions.

\section{Visualization of lipid rafts with cholera toxin B}

The stably transfected cells were plated on glass coverslips and analyzed by Vybrant ${ }^{\circledR}$ Lipid Raft Labeling Kits (Invitrogen, USA) according to the manufacturer's instructions.

\section{IHC and immunofluorescence (IF) analysis}

For experimental mouse or human intestinal and colorectal tissues, IHC and IF staining was performed as previously described $[20,21]$. The study methodologies were approved by the local ethics committee, and the following primary antibodies were used: AIBP (Abcam, ab81907, 1:300 dilution), APOA-I (Bioss, bs-0849R, 1:300 dilution) and CD31 antibody (Abcam, ab28364, 1:300 dilution). The corresponding secondary antibodies were used in accordance with the manufacturer's instructions.

\section{Quantitative RT-PCR}

Total RNA from cells or tissues was extracted using TRIzol reagent (Invitrogen, USA), and cDNA synthesis 
was performed using the PrimeScript ${ }^{\mathrm{TM}} \mathrm{RT}$ reagent Kit (Takara, China). Quantitative RT-PCR was carried out using the Bio-Rad CFX96 Touch system with Real-time PCR Master Mix (SYBR Green). The PCR primers are listed in Additional file 2: Table S2.

\section{Statistical analysis}

Statistical analyses between groups were performed by two-tailed Student's t-test to determine significance when only 2 groups were compared. Statistical comparisons among 3 or more groups were performed using one-way ANOVA followed by the Tukey test or Dunnett's test. Differences were considered significant at the level $P<0.05\left({ }^{*} P<0.05,{ }^{* *} P<0.005,{ }^{* * *} P<0.001\right)$. The data are expressed as the means \pm SDs. Kaplan-Meier curves were used to compare survival times among groups. All statistical analyses was performed using SPSS 16.0.

\section{Results \\ AIBP expression and APOA-I expression are associated with the malignant degree of intestinal tumors}

APOA-I is synthesized predominantly in the liver and small intestine [9], and AIBP is reportedly ubiquitously expressed in various organs [13], but their expression in malignant conditions of the gastrointestinal tract remains unknown. Here, we examined AIBP or APOA-I expression in normal intestinal epithelial tissues, adenomas (from Apc ${ }^{\mathrm{min} /+}$ mice ranging in age from 100-150 days), and large tumors $\left(\mathrm{Apc}^{\mathrm{min} /+}\right.$ mice ranging in age from 200 to 230 days) [22, 23]. The IHC and WB results showed that APOA-I expression was obviously decreased in the intestinal adenomas, while AIBP expression was slightly reduced compared with those in the normal tissues. All large tumors, whether in the intestine or colon, exhibited markedly weak staining of both APOA-I and AIBP compared with normal tissues (Fig. 1a, b). Moreover, we analyzed the expression of AIBP/APOA-I in 47 pairs of patients' cancerous and normal tissues. The results showed that both AIBP and APOA-I levels were significantly downregulated in stage III-IV Colorectal Cancer (CRC) compared to those in normal tissues or early stage I-II CRC (Fig. 1c, d; Additional file 2: Table S3). These results indicated that in the mouse adenomas, only APOA-I expression was significantly downregulated, whereas in the large tumors in mice and human advanced cancer tissues, the expression levels of both were consistently decreased to a minimum.

To further determine the correlation between AIBP/ APOA-I and the malignant degree of intestinal tumors, we analyzed their expression in colon cancer cell lines with different malignant degrees. The results showed that the expression patterns of AIBP and APOA-I were inconsistent in cancer cells with low malignancy, such as HT29, SW480, and LS174-T cells, while those in relatively highly malignant cells, such as SW620 and HCT116 cells, were consistently decreased to a minimum (Fig. 1e, f).

Taken together, these results suggested that low expression levels of both AIBP and APOA-I were associated with the malignant degree of intestinal tumors, and such low expression levels may provide a favorable condition for intestinal tumor progression.

\section{AIBP and APOA-I cooperate to inhibit tumor growth and metastasis}

AIBP and APOA-I have been reported to frequently work in a cooperative manner [24, 25]. The above results showed that simultaneous low expression of both is associated with the malignant degree of intestinal tumors, implying that the concurrent existence of AIBP and APOA-I may inhibit colon cancer cell-mediated tumor growth. To test this speculation, we established stably overexpressed colon cancer cell lines using HCT116 cells, which were designated as HCT116-NC, -AIBP, -APOA$\mathrm{I}$ and -AIBP+APOA-I (Additional file 1: Figure S1). Then, the cells were grafted into the flanks of nude mice by subcutaneous injection. Tumor growth was monitored in vivo after 21 days, and the results showed that the luminescence intensity was substantially weaker in tumors expressing HCT116-AIBP + APOA-I than that in tumors from the other three groups (Fig. 2a). Consistent results were acquired in the SW620-mediated xenograft tumor model (Fig. 2b, c; Additional file 2: Table S4a). To further determine the combined inhibitory effect of AIBP and APOA-I on tumor growth, we subcutaneously injected only HCT116-AIBP cells into the flanks of nude mice, and the APOA-I recombinant protein was then administered intravenously once every 3 days for 4 cycles. The tumors derived from HCT116-AIBP cells accompanied by APOA-I administration were markedly smaller than those derived from HCT116-NC, HCT116-AIBP, or APOA-I administration-alone cells and had reduced growth rates (Fig. 2d, e; Additional file 2: Table S4b and c). In this experiment, APOA-I overexpression or administration alone inhibited tumor growth to a certain extent, but this effect was significantly enhanced by the addition of AIBP.

To further examine the role of AIBP and/or APOAI in metastasis of colon cancer cells, the above stably transfected HCT116 cells were injected into the spleens of nude mice (Fig. 2f, g). Fewer liver metastatic foci were observed in the mice injected with HCT116AIBP + APOA-I cells compared to the other three groups. In parallel experiments, the mean survival time of HCT116-APOA-I + AIBP-implanted mice (35.4 \pm 4.0$)$ was prolonged by 7.7 days or 4.1 days compared with that 

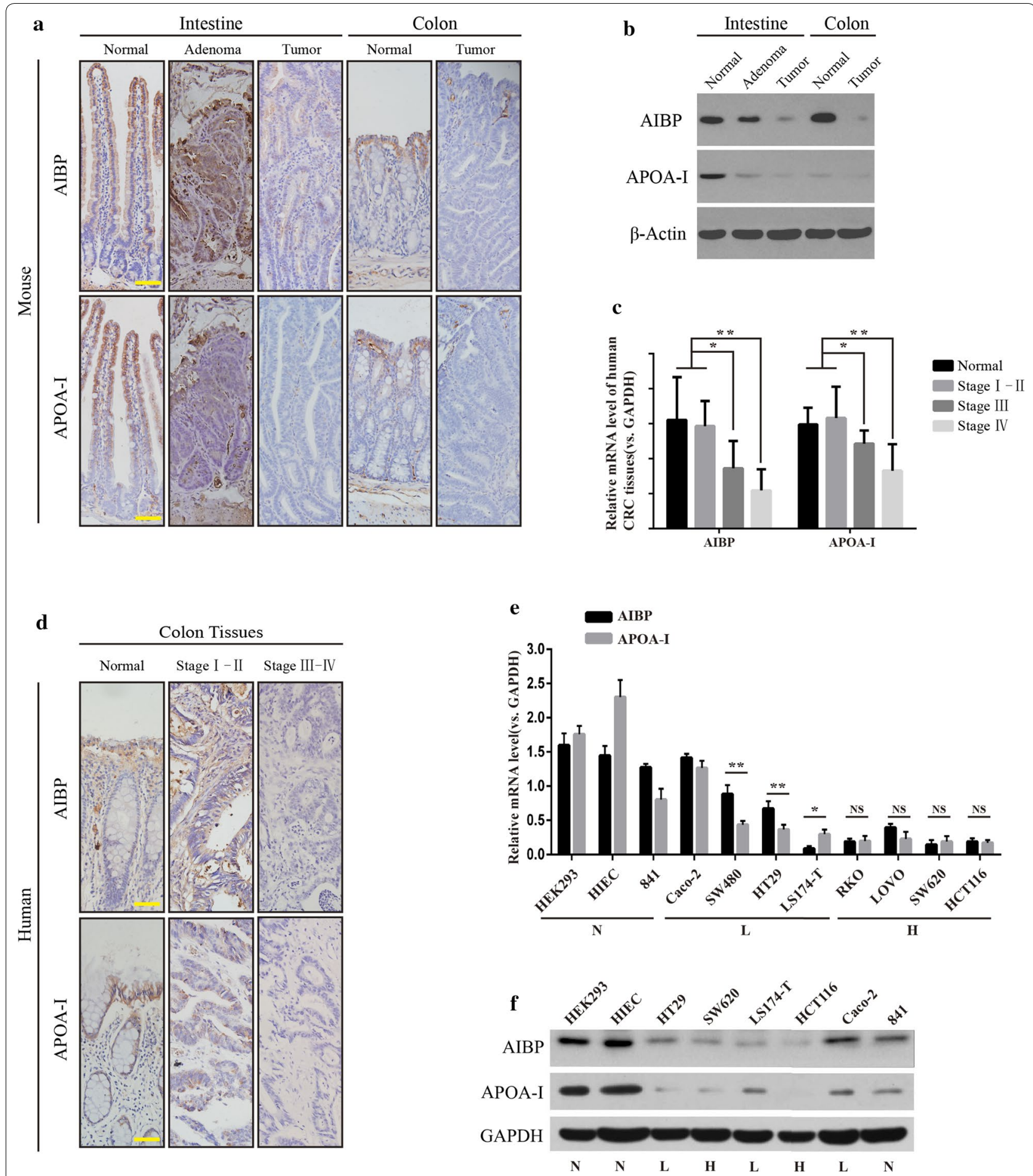

Fig. 1 APOA-1 and AIBP expression in normal and neoplastic intestinal tissues. a $\| \mathrm{HC}$ staining for AIBP and APOA-I in normal intestinal tissues, small intestinal adenoma, large tumors and colon tumors in C57BL/6 J-Apc Min/+ mice; scale bar, $50 \mu \mathrm{m}$. b Western blot for APOA-1 and AlBP in intestinal normal, adenoma and tumor tissues in C57BL/6 J-Apc ${ }^{\mathrm{Min} /+}$ mice. c AlBP or APOA-I mRNA expression in the patients' normal and cancerous tissues was evaluated according to the tumor differentiation stage $\left(n=47 ;{ }^{*} P<0.05 ;{ }^{* *} P<0.01 ;{ }^{* *} P<0.0001\right)$. $\mathbf{d}$ Staining for AIBP and APOA-I in human normal and malignant colon tissues from patients; scale bar, $50 \mu \mathrm{m}$. e, f $\mathrm{qPCR}$ and western blot results showing AIBP or APOA-I mRNA expression in various cell lines, including normal and colon cancer cell lines with a varying degree of malignancy. $N$, normal epithelial cells; L, low-malignant colon cancer cells; $\mathrm{H}$, high-malignant colon cancer cells (NS, no significant difference; ${ }^{*} P<0.05$; ${ }^{* *} P<0.01$ ) 

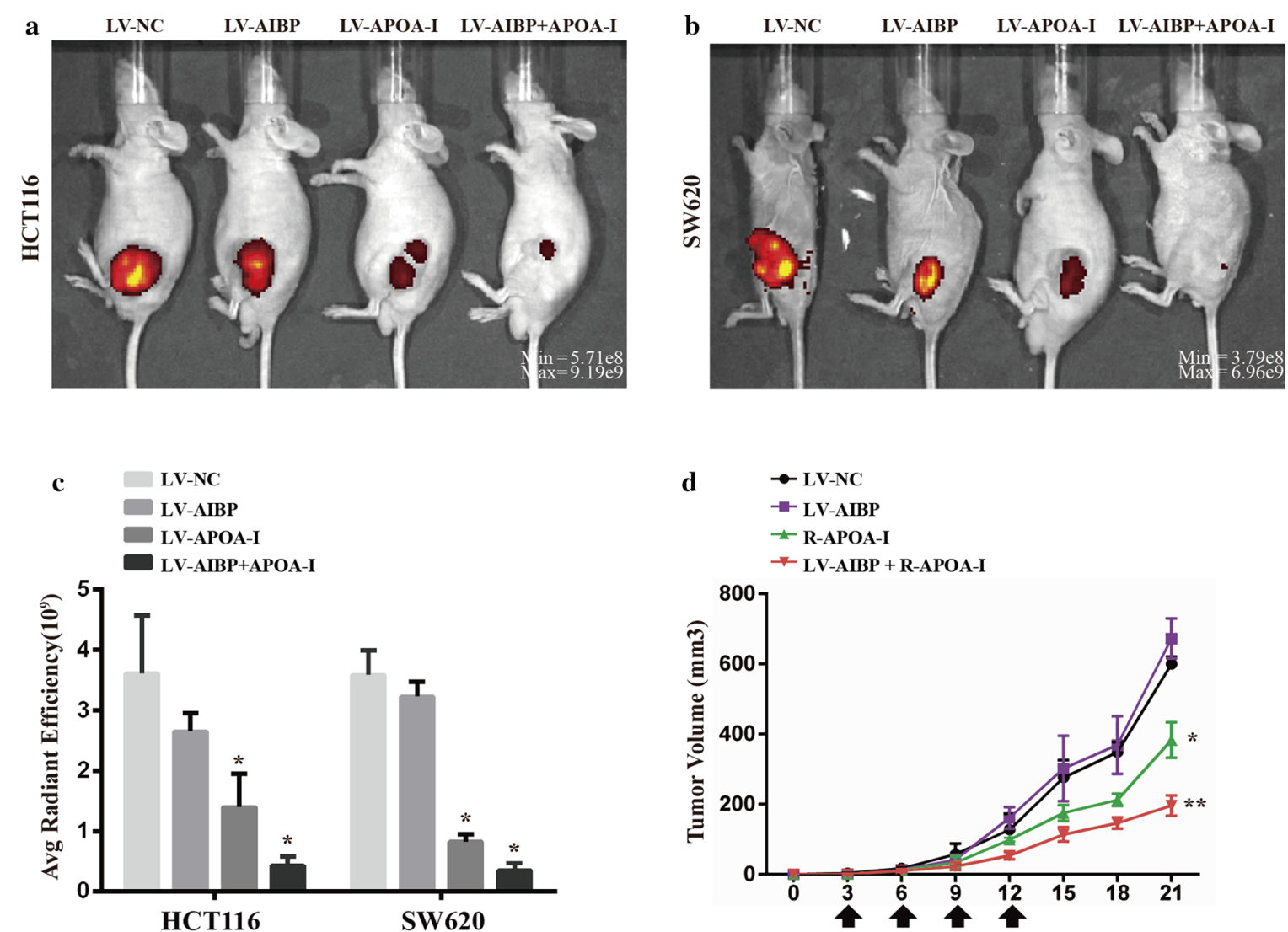

e
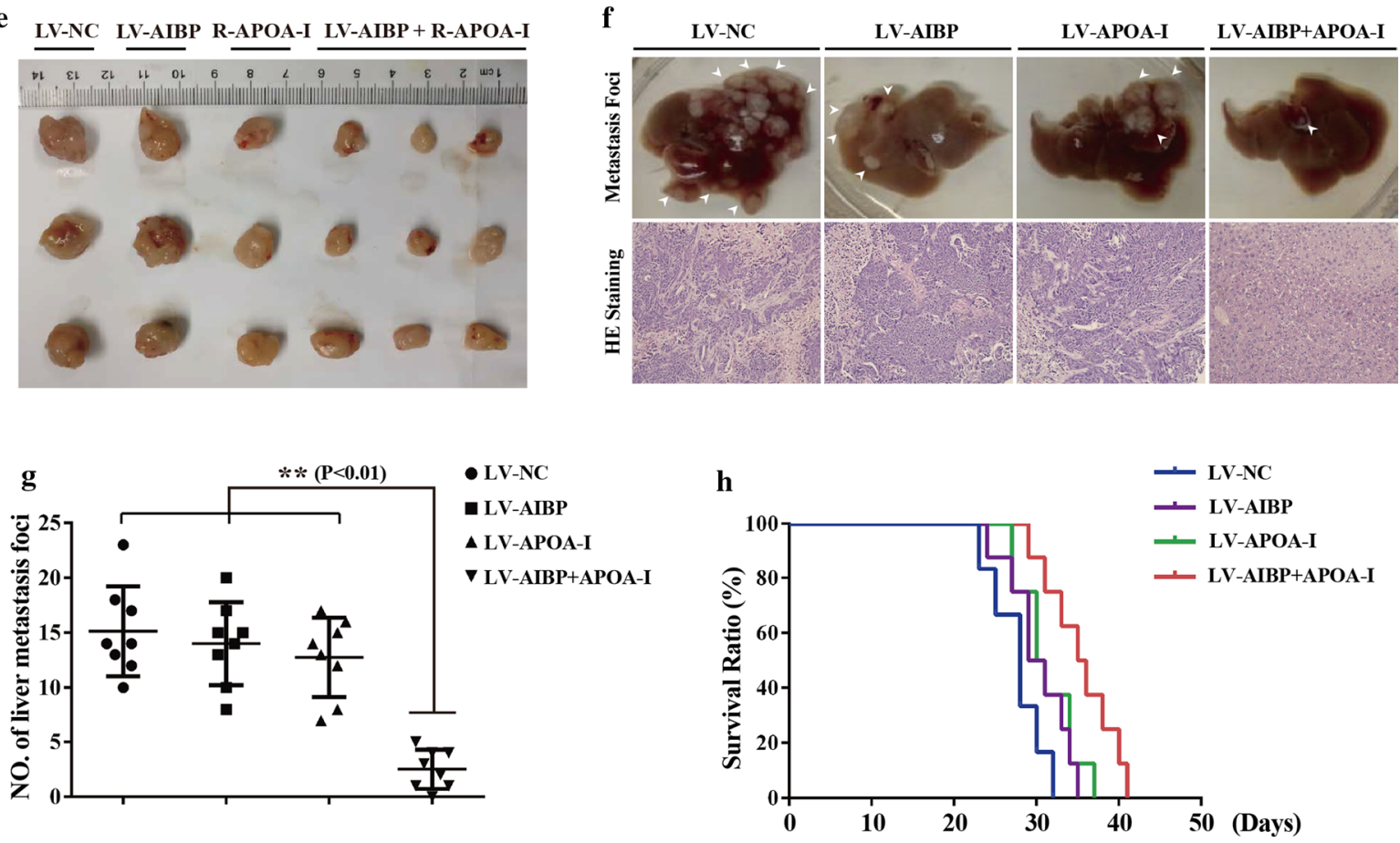
(See figure on previous page.)

Fig. 2 AIBP and APOA-I cooperate to inhibit tumor growth and metastasis. a-c Representative images and statistical analyses of tumors in mice inoculated with HCT116 (a) or SW620 cells (b) expressing the negative control (NC), AIBP, APOA-I and AIBP + APOA-I, and the average radiant efficiency $\left[\left(\mathrm{p} / \mathrm{s} / \mathrm{cm}^{2} / \mathrm{sr}\right] /\left(\mu \mathrm{W} / \mathrm{cm}^{2}\right)\right]$ of tumors in mice $(\mathbf{c})\left(\mathrm{n}=5 ;{ }^{*} P<0.05 ; * *<0.01\right)$. d The tumor growth rates were evaluated by calculating the tumor volume. e Representative tumors from mice injected with HCT116 cells expressing AIBP and subcutaneously administered APOA-I recombinant proteins (R-APOA-1, $0.5 \mathrm{mg} / \mathrm{kg}$ ) at the end stage (mean $\pm \mathrm{SD}, \mathrm{n}=5 ;{ }^{*} P<0.05 ;{ }^{* *} P<0.01$ ). $\mathbf{f}$ Representative picture and $\mathrm{HE}$ staining image after injection of the indicated cells. $\mathbf{g}$ Liver metastatic foci were quantified (mean $\pm S D, n=8,{ }^{* *} P<0.01$ ). $\mathbf{h}$ The survival rates of the indicated cell-transplanted mice ( $n=6,8,8$, and 8, respectively). Kaplan-Meier survival curves representing the percentages of live mice on the days indicated. Statistical significance among the studied groups was calculated using GraphPad Prism 6 software

of HCT116-NC or HCT116-APOA-I implanted mice, respectively (Fig. 2h; Additional file 2: Table S5).

Taken together, these results suggested that AIBP and APOA-I synergistically played a significant inhibitory role in colon cancer cell-mediated tumor growth and metastasis.

\section{Evaluation of the therapeutic effect of AIBP + APOA-I in $\mathrm{Apc}^{\mathrm{Min} /+}$ mice}

To further evaluate the combined therapeutic effect of AIBP and APOA-I on colon cancer intestinal neoplasia in $\mathrm{Apc}^{\mathrm{Min} /+}$ mice, we generated a recombinant protein containing AIBP fused to the C-terminal of full-length APOA-I and linked by peptides Pro-Gly-Ser-Gly-SerGly, which was designated as R-AIBP + APOA-I. The mice were treated according to the protocol described in Fig. 3a, and APOA-I mimetic peptides (D-4F) were used as positive controls, which have an excellent antitumor effect in multiple mouse tumor models [26-28]. To ensure successful administration, serum APOA-I and AIBP levels were monitored by ELISA assays (Additional file 1: Figure S2). The mice were sacrificed on the last day of the experiment, and the intestinal tumors were enumerated immediately. Statistical data showed that compared with BSA treatment, R-APOA-I treatment alone did not significantly affect the numbers of tumor nodules $(16.88 \pm 1.60$ vs. $18.33 \pm 2.26)$, whereas both $\mathrm{D}-4 \mathrm{~F}$ and R-AIBP + APOA-I treatment obviously reduced the numbers of tumor nodules $(9.50 \pm 0.99$ and $9.29 \pm 1.01$, respectively) (Fig. $3 \mathrm{~b}-\mathrm{d}$ ). To compare the therapeutic effects of D-4F and R-AIBP + APOA-I, we further calculated the numbers of tumors according to different sizes defined by the diameter of the tumor in $\mathrm{mm}(<1 \mathrm{~mm}$, 1-3 $\mathrm{mm}$ and $>3 \mathrm{~mm}$ ). The results showed that compared with BSA or APOA-I, D-4F treatment significantly reduced only the proportion of $1-3$ - $\mathrm{mm}$ tumors, whereas $\mathrm{R}$-AIPB + APOA-I treatment reduced the proportions of both $1-3-\mathrm{mm}$ and $>3-\mathrm{mm}$ tumors (Fig. 3e). These results suggested that AIBP + APOA-I induced an inhibitory effect on intestinal inherited tumors and had some advantages over D-4F in slowing tumor growth and limiting tumor size.

\section{AIBP and APOA-I in combination inhibited cell migration, cell invasion and tumor-induced angiogenesis}

To further explore why AIBP combined with APOA-I inhibited tumor growth and metastasis, we examined the effects of AIBP and/or APOA-I on colon cancer cell proliferation, viability, apoptosis, migration and invasion and tumor-induced angiogenesis. We observed that neither individual nor the combined expression of AIBP and APOA-I affected cell proliferation, viability or apoptosis, whereas migration and invasion abilities were significantly inhibited in cells expressing AIBP + APOA-I, but not in cells expressing either protein individually (Fig. 4a-h). Additionally, tumor-induced angiogenesis was evaluated by CD31 antibody staining, and the results showed that the average vessel density and area were lower in tumors derived from HCT116-AIBP + APOA-I cells than those in tumors derived from the other three groups (Fig. 4i, j). These data suggested that AIBP in combination with APOA-I can inhibit tumor-induced angiogenesis, cell migration and invasion, thus inhibiting tumor growth and metastasis.

\section{The cooperative inhibitory role is dependent on accelerating the cholesterol efflux}

AIBP in combination with APOA-I reportedly contributes to cholesterol efflux from various types of cells [13, $15,29]$. Thus, we hypothesized that the combined inhibitory effect of AIBP and APOA-I on colon cancer cells is probably achieved through a similar mechanism. To test this hypothesis, we first evaluated the effect of AIBP and/ or APOA-I on cholesterol efflux in HCT116 cells. Compared with individual overexpression, AIBP and APOA-I co-overexpression accelerated the cholesterol efflux to a larger extent (Fig. 5a). Meanwhile, the cells were treated with exogenous recombinant protein, and the results showed that APOA-I is required for cholesterol efflux, which was enhanced in an AIBP concentration-dependent manner (Fig. 5b). Accelerating the cholesterol efflux often induces a reduction in the lipid raft content in cells. Then, we evaluated the lipid raft content with $\mathrm{CTxB}$ staining. High, middle and low lipid raft contents were defined by the CTB-positive area per cell (high, $>4 \mu^{2}$; middle, $2-4 \mu \mathrm{m}^{2}$; low, $<2 \mu \mathrm{m}^{2}$ ). In the control group, 


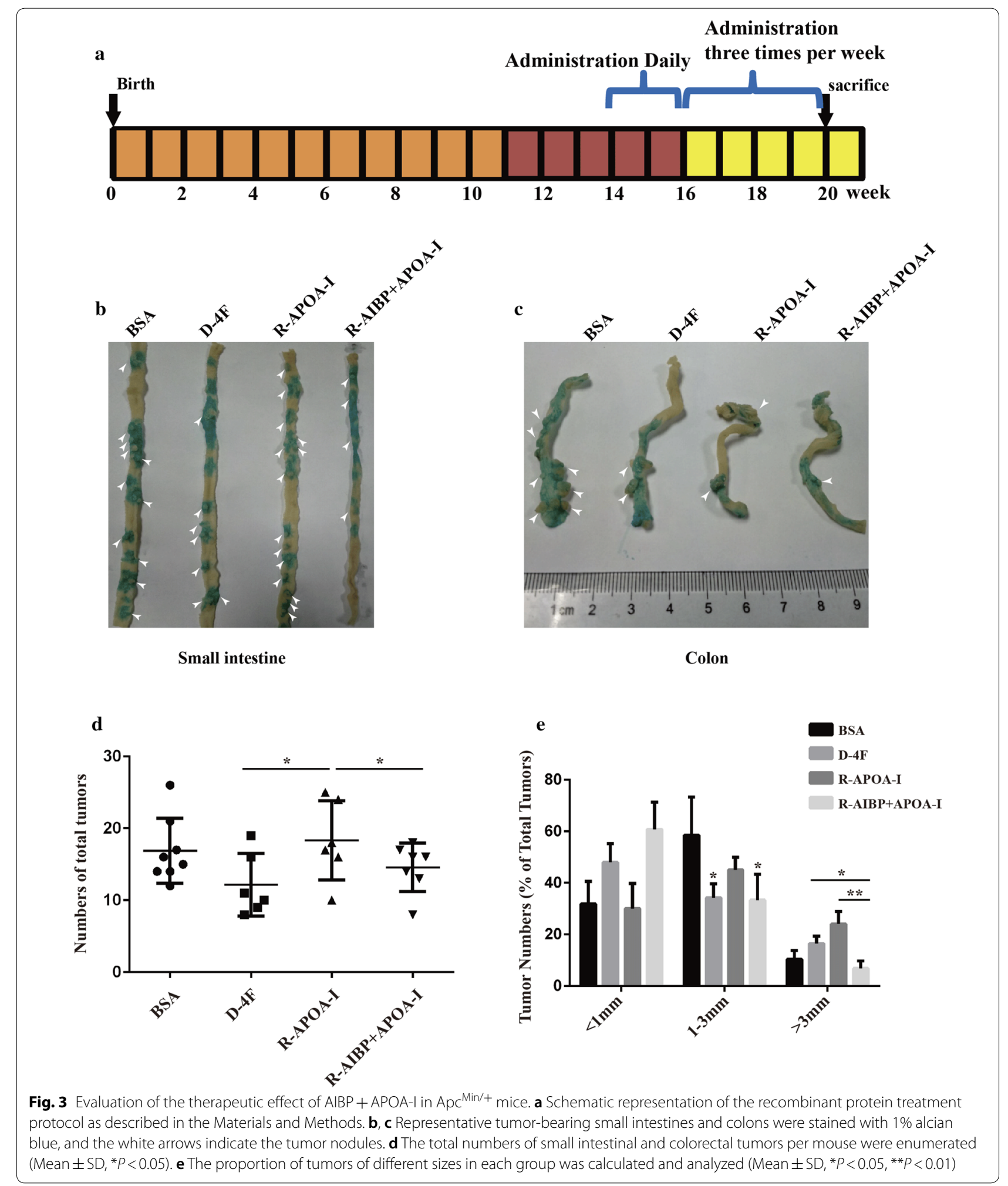

the cells with high, middle and low lipid raft contents accounted for $75 \%, 18 \%$ and $7 \%$ of all cells, respectively. No significant changes in these proportions were noted in the individual overexpression groups (APOA-I: high, 69\%; middle, 15\%; low, 16\%; AIBP: high, 67\%; middle, $21 \%$; low, $11 \%)$. However, in the co-overexpression group, 

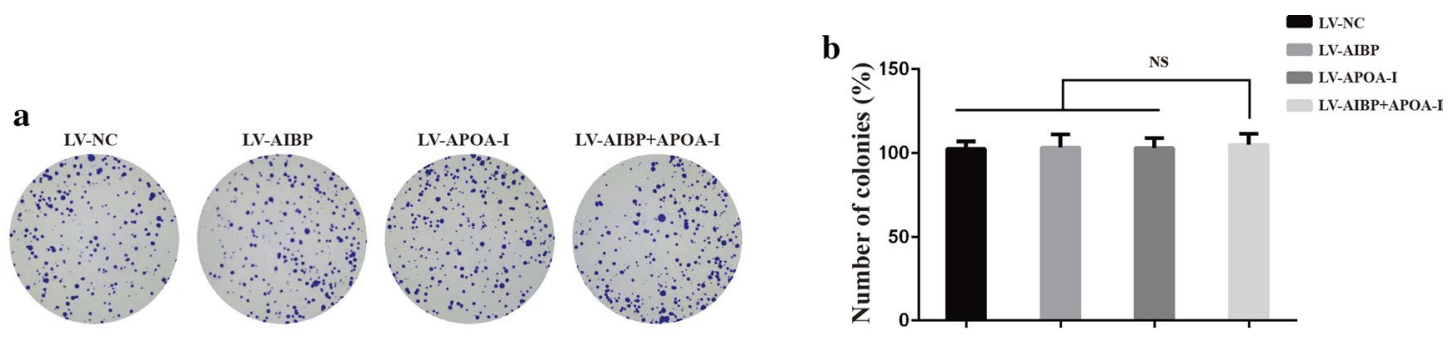

c
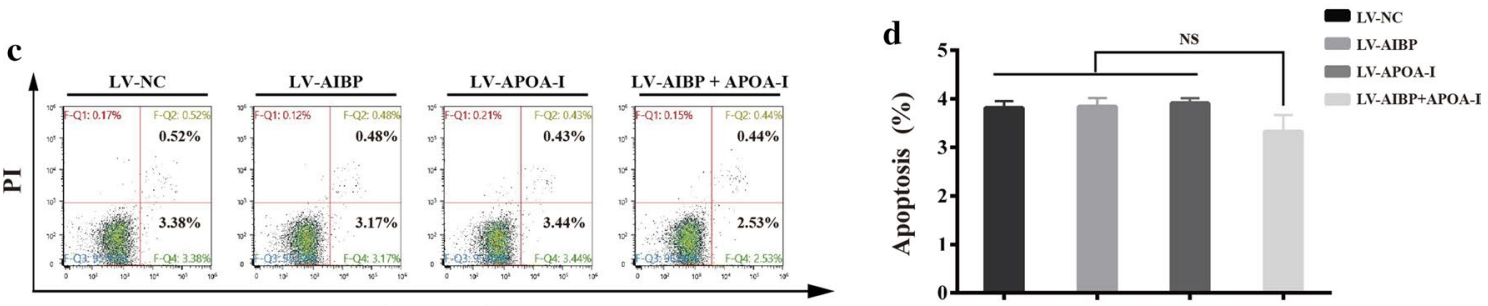

Annexin-V FITC
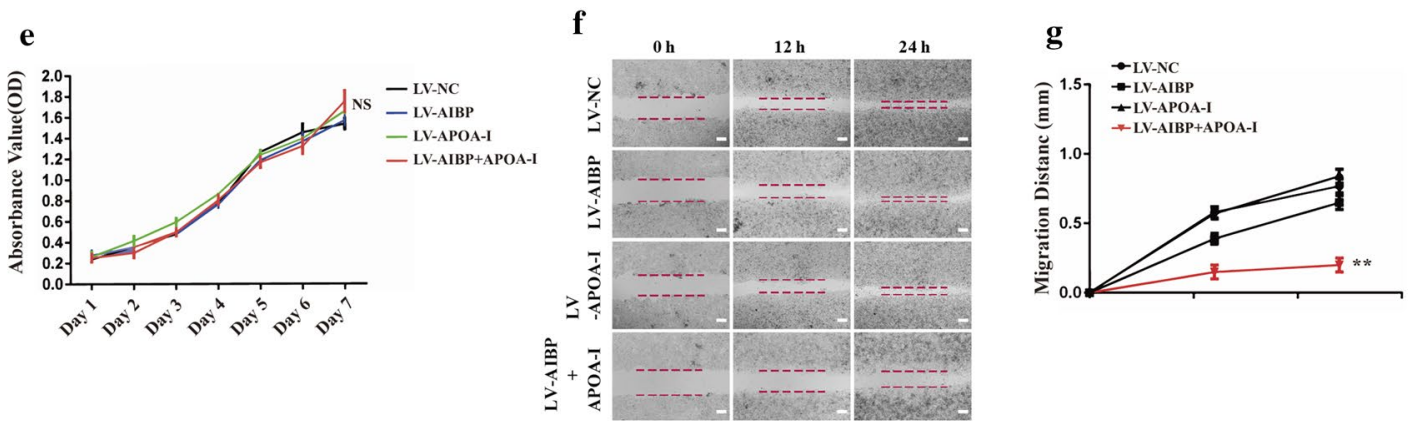

h

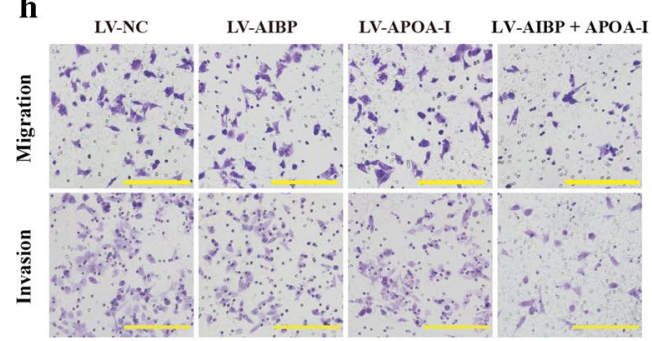

j

ติ

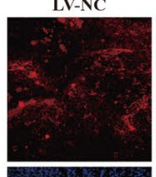

ลั

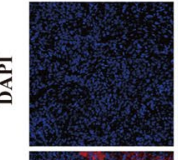

LV-AIBP

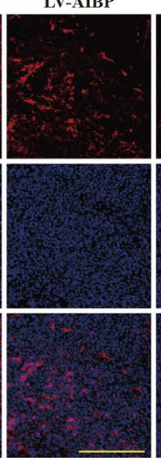

IV-APOA-I LY-AIBP + APOA-I

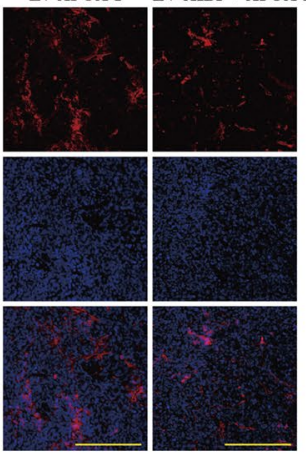

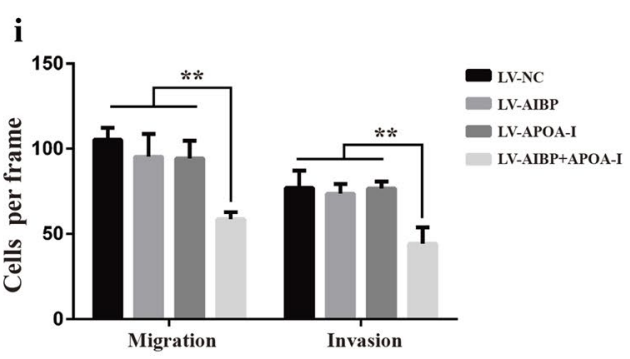

k

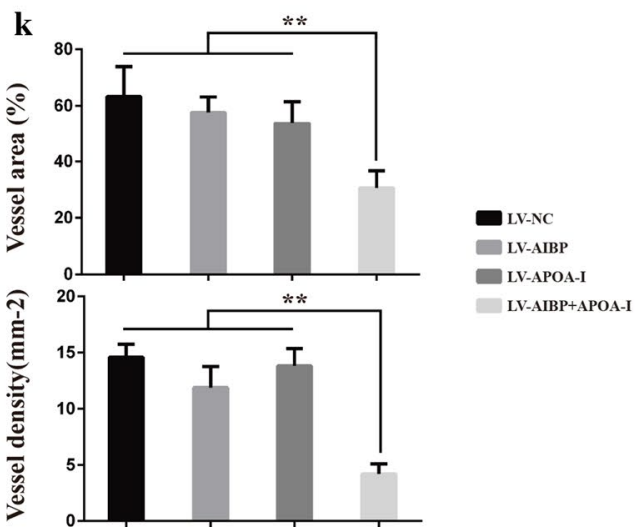


(See figure on previous page.)

Fig. 4 The effect of combined AIBP and APOA-I on colon cancer cells' biological behavior. $\mathbf{a}$, $\mathbf{b}$ Representative images and statistical analyses of clone formation (mean $\pm \mathrm{SD}, \mathrm{n}=3$, NS, no significant difference). $\mathbf{c}$, $\mathbf{d}$ Analysis of cell apoptosis by flow cytometry. e The CCK-8 assay for viability of the indicated cells from day 1 to day 7 (mean $\pm S D, n=3, N S$, no significant difference). $\mathbf{f}$ Wound healing assay for migration of the indicated cells. Representative images were taken at the indicated time points. Scale bar, $200 \mu \mathrm{m}$. $\mathbf{g}$ The corresponding migratory distance was quantified $(n=3$; ${ }^{*} P<0.05$; $\left.{ }^{* *} P<0.01\right)$. h Representative fields of the indicated cells passing through the transwell chambers; Scale bar, $100 \mu \mathrm{m}$. $\mathbf{i}$ The number of cells per frame was counted. $\mathbf{j}$ CD31 staining for tumor-induced angiogenesis. Scale bar, $100 \mu \mathrm{m}$. $\mathbf{k}$ Vessel density $\left(\mathrm{mm}^{2}\right)$ and vessel area (\%; mean \pm SD, $\left.n=5 ;{ }^{* *} P<0.01\right)$

the proportion of cells with a high lipid raft content was reduced to $40 \%$, and the proportions of cells with middle and low lipid raft contents increased to $35 \%$ and $25 \%$, respectively (Fig. 5c, d).

The integrity of lipid rafts is necessary for proper localization and functioning of migration- and invasionrelated proteins [6]. Localization of integrin $\beta_{1}$ and FAK [30, 31] or MT1-MMP and CAV1 [32-35] at lipid rafts is closely related to migration and invasion, respectively. We isolated cell raft fractions, and the blot results showed that in the positive control group, $\mathrm{M} \beta C D$ treatment markedly altered the locations of the above proteins on the lipid rafts. Consistent results were obtained in the cells co-overexpressing AIBP and APOA-I, suggesting that the combination of AIBP and APOA-I simulated the effect of $M B C D$ on membrane rafts and interfered with the migration- and invasion-related signaling pathway (Fig. 5e, f).

The above results implied that the inhibitory effect of AIBP and APOA-I on tumor growth is probably achieved by promoting cholesterol efflux. To further determine the mechanism, we treated mice inoculated with HCT116AIBP + APOA-I cells with CsA, which is a cholesterol efflux inhibitor. In vivo imaging results showed that CsA treatment had no significant effect on tumor growth mediated by HCT116-NC but obviously promoted tumor growth mediated by HCT116-AIBP + APOA-I (Fig. 6a, b). Moreover, we found that $10-\mu \mathrm{M}$ CsA treatment not only had no significant effect on colon cancer cell viability but can also effectively inhibit the cholesterol efflux induced by AIBP + APOA-I (Additional file 1: Figure S3). Further analysis showed that CsA treatment also abolished the inhibitory effect of AIBP + APOA-I on cell migration and invasion and tumor-induced angiogenesis (Fig. 6c-f).

Collectively, our data indicate that the anti-tumor effect of AIBP and APOA-I in combination is mainly dependent on promoting the cholesterol efflux.

\section{Discussion}

Recently, disruption of lipid rafts of malignant cells has been considered an essential strategy for the prevention and treatment of cancer [6]. In this study, we found that low expression levels of AIBP and APOA-I are associated with the degree of malignancy in intestinal tumors. Combined with AIBP and APOA-I inhibited tumor growth and metastasis as well as cell migration, invasion and tumor-induced angiogenesis. Mechanically, cholesterol efflux promoted by AIBP + APOA-I interfered with the raft-related signaling pathway.

Prior studies have shown that AIBP often cooperates with APOA-I to regulate the RCT pathway in various types of cells. However, the expression patterns of AIBP and APOA-I in malignant tissues remain poorly understood. In this study, we found that both AIBP expression and APOA-I expression decreased gradually with progression from an adenoma to an advanced tumor. In this process, the decreasing rates of AIBP and APOA-I levels are not entirely synchronized. For example, in low-malignancy adenoma or colon cancer cells, the expression of one of these proteins was always significantly higher or lower than that of the other. However, in advanced tumors or high-malignancy colon cancer cells, the expression of both proteins was consistently decreased to a minimum. These results suggested that simultaneous low expression levels of both proteins likely represent a critical step in the malignant transformation of tumor cells. Therefore, the expression levels of AIBP and APOA-I can be used as an indicator of malignancy of intestinal cancer.

APOA-I was reported to have anti-tumor activity in some xenograft tumor models $[10,36]$, but its therapeutic effect is limited in the inherited tumor model [37]. Consistently, we found that APOA-I treatment alone can inhibit colon cancer cell-mediated tumor growth to a certain extent but has no apparent inhibitory effect on tumor growth in $\mathrm{Apc}^{\mathrm{min} /+}$ mice. However, the addition of AIBP enhanced the anti-tumor effect of APOA-I both in xenograft and inherited tumor models. Similar to in vitro studies, APOA-I treatment alone can induce cholesterol efflux to a certain degree but was insufficient to produce significant changes in cellular behavior due to a lower rate of cholesterol efflux. In contrast, AIBP hardly promoted cholesterol efflux when APOA-I was absent due to the lack of a cholesterol acceptor. Thus, APOA-I is necessary for cell cholesterol efflux, whereas AIBP serves as an accelerator to augment this effect triggered by APOA-I. These 


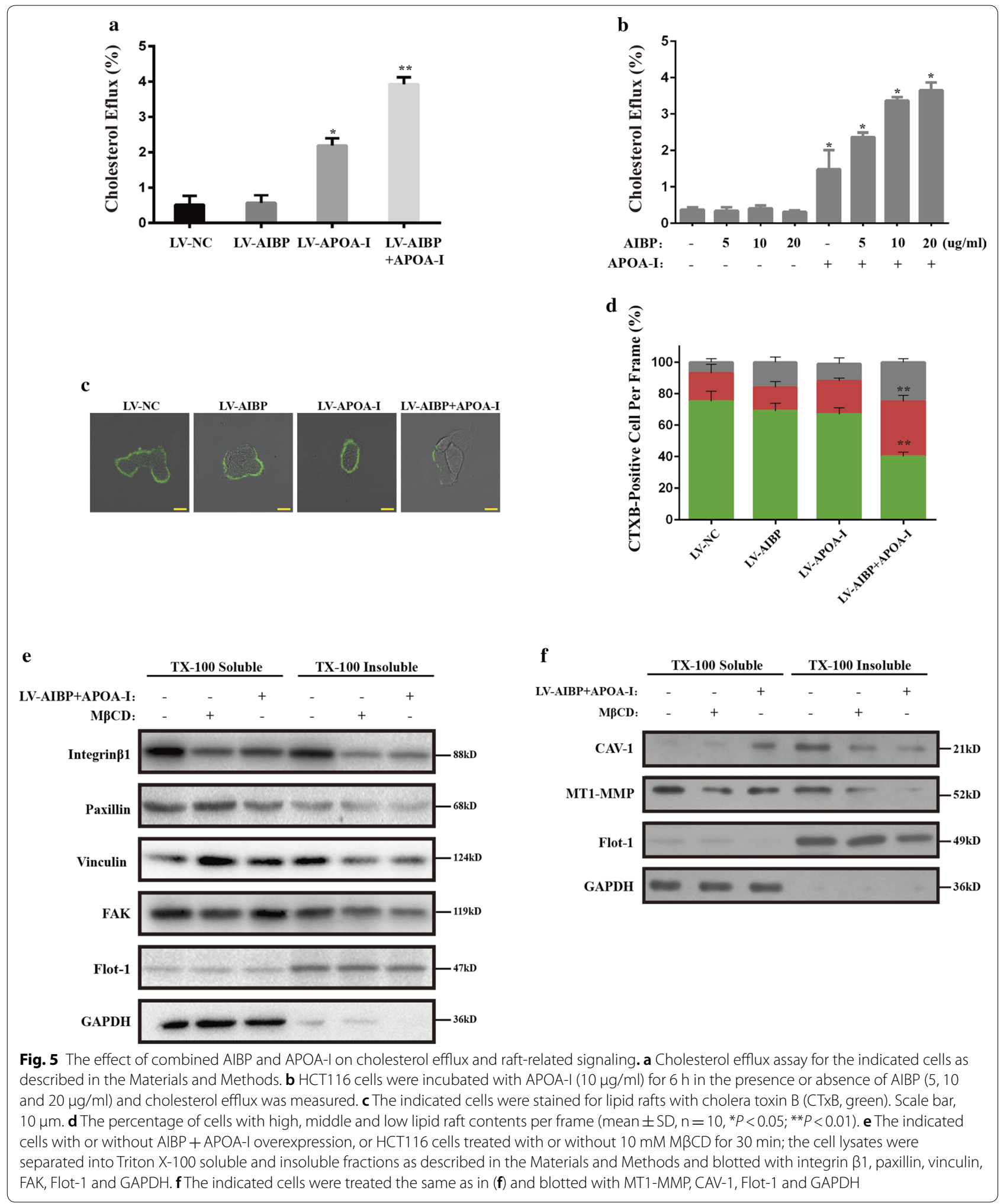




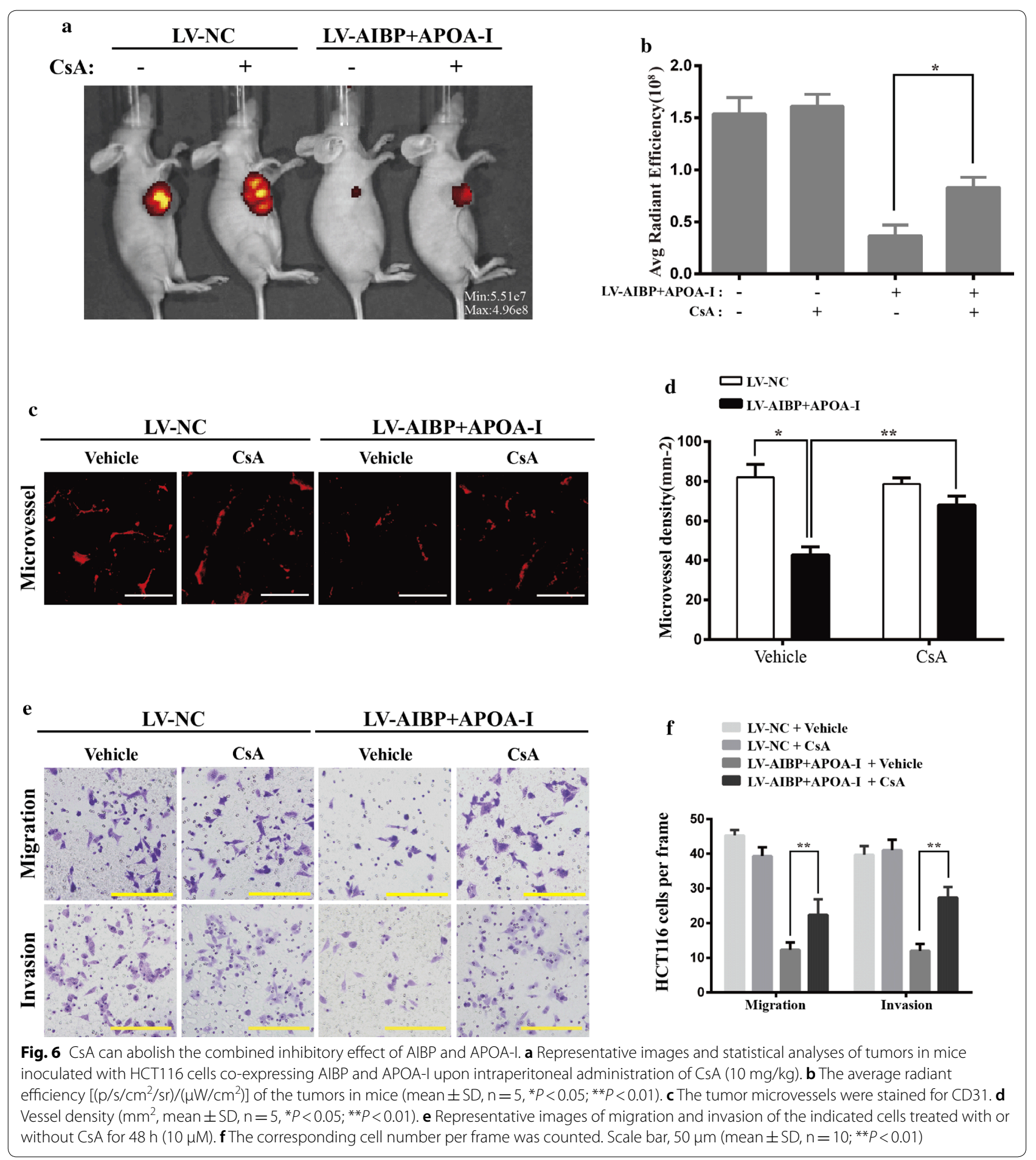

results suggested that the combined anti-tumor effect is closely related to enhanced cholesterol efflux. Whether AIBP in combination with APOA-I promotes other anti-tumor pathways, such as anti-inflammatory or anti-oxidation pathways, requires further study.
Cell migration and invasion are essential processes for cancer metastasis. Assembly of the integrin-based adhesion structure is critical for effective cell movement. Recent evidence suggests that integrin $\beta 1$ clustering and functioning are regulated by membrane rafts, which 
provide a large platform for assembling different proteins to facilitate the migration-related signaling pathway [31]. Moreover, MT1-MMP, as one of the raft-affiliated matrix metalloproteinases (MMPs), has been shown to contribute to the invasive abilities of tumor cells by activating pro-MMP-2 [32, 38, 39]. In the present study, AIBP combined with APOA-I promoted cholesterol efflux from the membrane and directly affected the tight packing and stabilization of lipid rafts, thus impairing proper localization of integrin $\beta 1$ and MT1-MMP and eventually migration- and invasion-related signaling cascades. On the other hand, the combination of AIBP and APOA-I inhibited tumor-induced angiogenesis, which is an essential process for tumor cell growth and metastasis. Therefore, the combination of AIBP and APOA-I not only restricts cancer cell migration and invasion but also blocks hematogenous metastasis.

APOA-I-dependent cholesterol efflux involves a $\mathrm{Ca}^{2+}$-dependent endocytic pathway, followed by recycling and subsequent release of the nascent lipoprotein particle from the cell $[40,41]$. Therefore, CsA acts as a potent inhibitor of cholesterol efflux by suppressing the internalization of APOA-I [42, 43]. Here, CsA treatment compromised the inhibitory role of AIBP combined with APOA-I in colon cancer cell-mediated tumor growth as well as cell migration, invasion and tumor-induced angiogenesis. These results suggested that the anti-tumor activity of AIBP combined with APOA-I is dependent on cholesterol efflux.

\section{Conclusions}

In this study, we found that the combination of AIBP and APOA-I exerts a significant inhibitory effect on intestinal tumor growth and liver metastasis. This effect was achieved by promoting cholesterol efflux and subsequent suppression of the lipid raft-associated signaling pathway. Taken together, these findings suggest that AIBP and APOA-I in combination serve as a natural cholesteroldepleting agent and could be of therapeutic value in preventing metastasis of human CRC and potentially other cancers.

\section{Additional files}

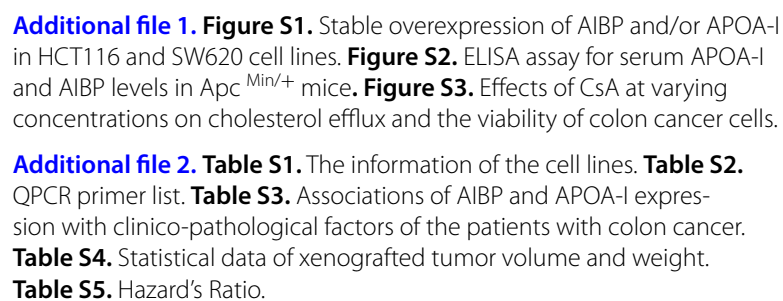

\section{Abbreviations}

AIBP: APOA-I binding protein; M $\beta C D$ : methyl- $\beta$-cyclodextrin; MT1-MMP: membrane type I matrix metalloproteinase; CAV-1: caveolin-1.

\section{Acknowledgements}

We thank Mr. Chi Liu at the Department of Nephrology, Xinqiao Hospital for assistance with editing the manuscript. We thank Mr. Xiao Yang at the State Key Laboratory of Proteomics, Genetic Laboratory of Development and Diseases, Institute of Biotechnology, Beijing, China for useful suggestions.

\section{Authors' contributions}

TZ carried out all experiments, performed the statistical analysis. TZ and GW drafted the manuscript. QW and YW participated in the mouse studies, especially the xenograft model and metastatic model with the indicated cells. FW, JW and YS conceived of the study and participated in its design and coordination. All authors read and approved the final manuscript.

\section{Funding}

This study was partially supported by grants from the National Natural Science Foundation of China (11572064, 31771599), the National Key Research and Development Program of China (2016YFC1102305, 2016YFC1101101), and the Fundamental Research Funds for the Central Universities(106112017CDJZ RPY0012, 106112017CDJXY230002) as well as the Public Experiment Center of the state Bioindustrial Base (Chongqing), China.

\section{Availability of data and materials}

The datasets used and/or analysed during the current study are available from the corresponding author on reasonable request.

\section{Ethics approval and consent to participate}

The study protocol was conducted in accordance with the Declaration of Helsinki and approved by the Institutional Review Board of Chongqing Third Military Medical University. Informed consent was received from all patients included in the current study or their direct relatives. The animal study was approved by Laboratory Animal Welfare and Ethics Committee of the Third Military Medical University.

\section{Consent for publication}

Not applicable.

\section{Competing interests}

The authors declare that they have no competing interests.

Received: 23 February 2019 Accepted: 7 May 2019

Published online: 17 May 2019

References

1. Simons K, Ikonen E. How cells handle cholesterol. Science. 2000;290:1721-6.

2. Silvente-Poirot S, Poirot M. Cancer. Cholesterol and cancer, in the balance. Science. 2014;343:1445-6.

3. Jacobs RJ, Voorneveld PW, Kodach LL, Hardwick JC. Cholesterol metabolism and colorectal cancers. Curr Opin Pharmacol. 2012;12:690-5.

4. Wang B, Rong X, Palladino END, Wang J, Fogelman AM, Martin MG, Alrefai WA, Ford DA, Tontonoz P. Phospholipid remodeling and cholesterol availability regulate intestinal stemness and tumorigenesis. Cell Stem Cell. 2018;22(206-220):e204.

5. Wang C, Li P, Xuan J, Zhu C, Liu J, Shan L, Du Q, Ren Y, Ye J. Cholesterol enhances colorectal cancer progression via ROS elevation and MAPK signaling pathway activation. Cell Physiol Biochem. 2017;42:729-42.

6. Hryniewicz-Jankowska A, Augoff K, Biernatowska A, Podkalicka J, Sikorski AF. Membrane rafts as a novel target in cancer therapy. Biochim Biophys Acta. 2014;1845:155-65.

7. Simons K, Ikonen E. Functional rafts in cell membranes. Nature. 1997;387:569-72.

8. Brown DA, London E. Functions of lipid rafts in biological membranes. Annu Rev Cell Dev Biol. 1998;14:111-36.

9. Zamanian-Daryoush M, DiDonato JA. Apolipoprotein A-I and cancer. Front Pharmacol. 2015;6:265. 
10. Zamanian-Daryoush M, Lindner D, Tallant TC, Wang Z, Buffa J, Klipfell E, Parker Y, Hatala D, Parsons-Wingerter P, Rayman P, et al. The cardioprotective protein apolipoprotein $\mathrm{A} 1$ promotes potent anti-tumorigenic effects. J Biol Chem. 2013;288:21237-52.

11. van Duijnhoven FJ, Bueno-De-Mesquita HB, Calligaro M, Jenab M, Pischon T, Jansen EH, Frohlich J, Ayyobi A, Overvad K, Toft-Petersen AP, et al. Blood lipid and lipoprotein concentrations and colorectal cancer risk in the European prospective investigation into cancer and nutrition. Gut. 2011;60:1094-102.

12. Gkouskou KK, loannou M, Pavlopoulos GA, Georgila K, Siganou A, Nikolaidis G, Kanellis DC, Moore S, Papadakis KA, Kardassis D, et al. Apolipoprotein A-l inhibits experimental colitis and colitis-propelled carcinogenesis. Oncogene. 2016;35:2496-505.

13. Fang L, Choi SH, Baek JS, Liu C, Almazan F, Ulrich F, Wiesner P, Taleb A, Deer $\mathrm{E}$, Pattison J, et al. Control of angiogenesis by AIBP-mediated cholesterol efflux. Nature. 2013;498:118-22.

14. Mao R, Meng S, Gu Q, Araujo-Gutierrez R, Kumar S, Yan Q, Almazan F, Youker KA, Fu Y, Pownall HJ, et al. AlBP limits angiogenesis through gamma-secretase-mediated upregulation of notch signaling. Circ Res. 2017;120:1727-39.

15. Zhang M, Li L, Xie W, Wu JF, Yao F, Tan YL, Xia XD, Liu XY, Liu D, Lan G, et al. Apolipoprotein A-1 binding protein promotes macrophage cholesterol efflux by facilitating apolipoprotein A-1 binding to $A B C A 1$ and preventing ABCA1 degradation. Atherosclerosis. 2016;248:149-59.

16. Sviridov DD, Ehnholm C, Tenkanen H, Pavlov M, Safonova IG, Repin VS. Studies on the proteins involved in the interaction of high-density lipoprotein with isolated human small intestine epithelial cells. FEBS Lett. 1992;303:202-4.

17. Qazi AK, Hussain A, Khan S, Aga MA, Behl A, Ali S, Singh SK, Taneja SC, Shah BA, Saxena AK, et al. Quinazoline based small molecule exerts potent tumour suppressive properties by inhibiting PI3 K/Akt/FoxO3a signalling in experimental colon cancer. Cancer Lett. 2015;359:47-56.

18. Xu C-S, Wang Z-F, Huang X-D, Dai L-M, Cao C-J, Li Z-Q. Involvement of ROS-alpha $v$ beta 3 integrin-FAK/Pyk2 in the inhibitory effect of melatonin on U251 glioma cell migration and invasion under hypoxia. J Transl Med. 2015;13:95.

19. Wu J, Ji A, Wang X, Zhu Y, Yu Y, Lin Y, Liu Y, Li S, Liang Z, Xu X, et al. MicroRNA-195-5p, a new regulator of Fra-1, suppresses the migration and invasion of prostate cancer cells. J Transl Med. 2015;13:289.

20. Furuya H, Shimizu Y, Tamashiro PM, lino K, Bielawski J, Chan OTM, Pagano I, Kawamori T. Sphingosine kinase 1 expression enhances colon tumor growth. J Transl Med. 2017;15:120.

21. Zakharova IS, Zhiven MK, Saaya SB, Shevchenko Al, Smirnova AM, Strunov A, Karpenko AA, Pokushalov EA, Ivanova LN, Makarevich PI, et al. Endothelial and smooth muscle cells derived from human cardiac explants demonstrate angiogenic potential and suitable for design of cell-containing vascular grafts. J Transl Med. 2017;15:54.

22. Halberg RB, Waggoner J, Rasmussen K, White A, Clipson L, Prunuske AJ, Bacher JW, Sullivan R, Washington MK, Pitot HC, et al. Long-lived Min mice develop advanced intestinal cancers through a genetically conservative pathway. Cancer Res. 2009;69:5768-75.

23. Zhong Z, Zhai Y, Bu P, Shah S, Qiao L. Papilloma-pseudovirus eradicates intestinal tumours and triples the lifespan of $\mathrm{Apc}(\mathrm{Min} /+)$ mice. Nat Commun. 2017:8:15004.

24. Ritter M, Buechler C, Boettcher A, Barlage S, Schmitz-Madry A, Orso E, Bared SM, Schmiedeknecht G, Baehr CH, Fricker G, Schmitz G. Cloning and characterization of a novel apolipoprotein A-l binding protein, Al-BP, secreted by cells of the kidney proximal tubules in response to $\mathrm{HDL}$ or ApoA-I. Genomics. 2002;79:693-702.

25. Fang L, Miller YI. Targeted cholesterol efflux. Cell Cycle. 2013;12:3345-6.

26. Reddy ST, Navab M, Anantharamaiah GM, Fogelman AM. Apolipoprotein A-I mimetics. Curr Opin Lipidol. 2014;25:304-8.

27. Su F, Grijalva V, Navab K, Ganapathy E, Meriwether D, Imaizumi S, Navab M, Fogelman AM, Reddy ST, Farias-Eisner R. HDL mimetics inhibit tumor development in both induced and spontaneous mouse models of colon cancer. Mol Cancer Ther. 2012;11:1311-9.

28. Ganapathy E, Su F, Meriwether D, Devarajan A, Grijalva V, Gao F, Chattopadhyay A, Anantharamaiah GM, Navab M, Fogelman AM, et al. D-4F, an apoA-I mimetic peptide, inhibits proliferation and tumorigenicity of epithelial ovarian cancer cells by upregulating the antioxidant enzyme MnSOD. Int J Cancer. 2012;130:1071-81.

29. Jha KN, Shumilin IA, Digilio LC, Chertihin O, Zheng H, Schmitz G, Visconti PE, Flickinger CJ, Minor W, Herr JC. Biochemical and structural characterization of apolipoprotein A-I binding protein, a novel phosphoprotein with a potential role in sperm capacitation. Endocrinology. 2008;149:2108-20.

30. Jeon JH, Kim SK, Kim HJ, Chang J, Ahn CM, Chang YS. Lipid raft modulation inhibits NSCLC cell migration through delocalization of the focal adhesion complex. Lung Cancer. 2010;69:165-71.

31. Leitinger $B, \operatorname{Hogg} N$. The involvement of lipid rafts in the regulation of integrin function. J Cell Sci. 2002;115:963-72.

32. Galvez BG, Matias-Roman S, Albar JP, Sanchez-Madrid F, Arroyo AG. Membrane type 1-matrix metalloproteinase is activated during migration of human endothelial cells and modulates endothelial motility and matrix remodeling. J Biol Chem. 2001;276:37491-500.

33. Labrecque L, Nyalendo C, Langlois S, Durocher Y, Roghi C, Murphy G, Gingras D, Beliveau R. Src-mediated tyrosine phosphorylation of caveolin-1 induces its association with membrane type 1 matrix metalloproteinase. J Biol Chem. 2004;279:52132-40.

34. Yamaguchi H, Takeo Y, Yoshida S, Kouchi Z, Nakamura Y, Fukami K. Lipid rafts and caveolin-1 are required for invadopodia formation and extracellular matrix degradation by human breast cancer cells. Cancer Res. 2009;69:8594-602.

35. Yang H, Guan L, Li S, Jiang Y, Xiong N, Li L, Wu C, Zeng H, Liu Y. Mechanosensitive caveolin-1 activation-induced PI3 K/Akt/mTOR signaling pathway promotes breast cancer motility, invadopodia formation and metastasis in vivo. Oncotarget. 2016;7:16227-47.

36. Su F, Kozak KR, Imaizumi S, Gao F, Amneus MW, Grijalva V, Ng C, Wagner A, Hough G, Farias-Eisner G, et al. Apolipoprotein A-I (apoA-I) and apoA-I mimetic peptides inhibit tumor development in a mouse model of ovarian cancer. Proc Natl Acad Sci USA. 2010;107:19997-20002.

37. Cedó L, García-León A, Baila-Rueda L, Santos D, Grijalva V, MartínezCignoni MR, Carbó JM, Metso J, López-Vilaró L, Zorzano A, et al. ApoA-I mimetic administration, but not increased apoA-l-containing HDL, inhibits tumour growth in a mouse model of inherited breast cancer. Sci Rep. 2016;6:36387.

38. Li Y, Kuscu C, Banach A, Zhang Q, Pulkoski-Gross A, Kim D, Liu J, Roth E, Li E, Shroyer KR, et al. miR-181a-5p inhibits cancer cell migration and angiogenesis via downregulation of matrix metalloproteinase-14. Cancer Res. 2015;75:2674-85.

39. Perentes JY, Kirkpatrick ND, Nagano S, Smith EY, Shaver CM, Sgroi D, Garkavtsev I, Munn LL, Jain RK, Boucher Y. Cancer cell-associated MT1MMP promotes blood vessel invasion and distant metastasis in triplenegative mammary tumors. Cancer Res. 2011;71:4527-38.

40. Smith JD, Le GoffW, Settle M, Brubaker G, Waelde C, Horwitz A, Oda MN. ABCA1 mediates concurrent cholesterol and phospholipid efflux to apolipoprotein A-I. J Lipid Res. 2004;45:635-44.

41. Takahashi Y, Smith JD. Cholesterol efflux to apolipoprotein Al involves endocytosis and resecretion in a calcium-dependent pathway. Proc Natl Acad Sci USA. 1999;96:11358-63.

42. Nagao K, Maeda M, Manucat NB, Ueda K. Cyclosporine A and PSC833 inhibit ABCA1 function via direct binding. Biochim Biophys Acta. 2013;1831:398-406.

43. Le GoffW, Peng DQ, Settle M, Brubaker G, Morton RE, Smith JD. Cyclosporin $A$ traps $A B C A 1$ at the plasma membrane and inhibits $A B C A 1-$ mediated lipid efflux to apolipoprotein A-I. Arterioscler Thromb Vasc Biol. 2004;24:2155-61.

\section{Publisher's Note}

Springer Nature remains neutral with regard to jurisdictional claims in published maps and institutional affiliations. 